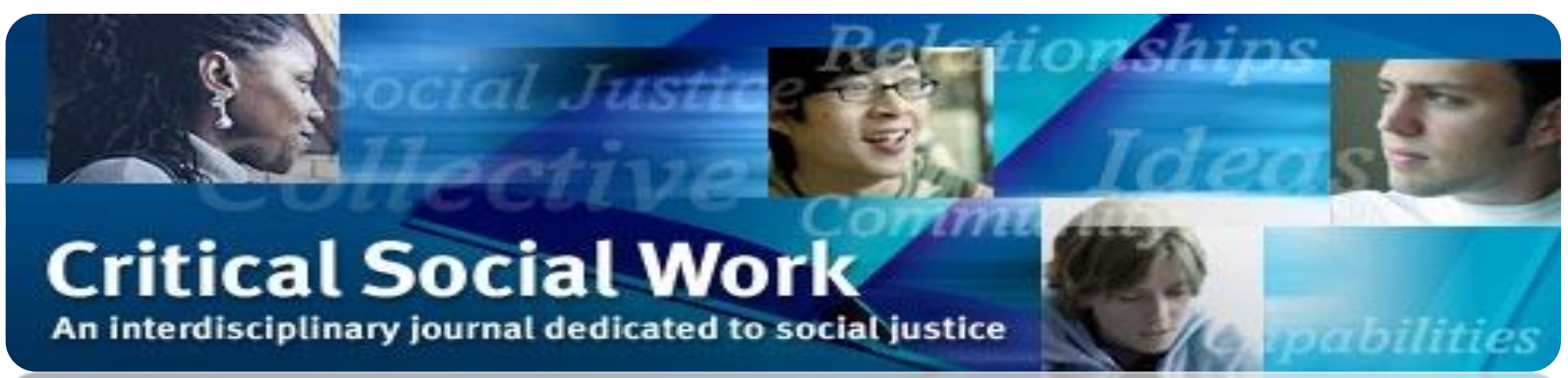

Critical Social Work

School of Social Work

University of Windsor

401 Sunset Avenue

Windsor, Ont.

Canada N9B 3P4

Email: cswedit@uwindsor.ca

Publication details, including instructions for authors and subscription information can be found at http://uwindsor.ca/criticalsocialwork

Link to article:

http://www1.uwindsor.ca/criticalsocialwork/barriers_calling_911

Critical Social Work, 2014 Vol. 15, No. 1 


\title{
Barriers to Calling 9-1-1 during Overdose Emergencies in a Canadian Context
}

\section{Critical Social Work 15(1)}

\author{
Kayla M. Follett ${ }^{1}$, Anthony Piscitelli ${ }^{1}$, Michael Parkinson ${ }^{1}$, and Felix Munger ${ }^{2}$ \\ ${ }^{1}$ Waterloo Region Crime Prevention Council; ${ }^{2}$ Wilfrid Laurier University
}

\section{Author Note}

We extend a sincere thank you to the 450 people who generously gave their time and experience to the survey team. We are grateful for their participation, without which this study would not exist. We would also like to thank Keely Phillips for her rigorous research support.

\begin{abstract}
Research has shown there are notable barriers to calling 9-1-1 during accidental overdose emergencies. Overdose is a significant health and social justice concern, yet Canadian researchers have not explored the existence or prevalence of these systemic obstacles. The current case study examines the barriers to calling 9-1-1 that people face in Southern Ontario when confronted with accidental overdose incidents. The locality of this study is particularly suitable as Wellington County, that is, Waterloo Region and Guelph are socio-demographically similar to Ontario and Canada. Barriers were assessed by surveying individuals that have or currently use drugs $(\mathrm{n}=291)$ and are clients of local methadone clinics or outreach services. Data were explored using frequency tables and then compared using crosstabulations. The findings of this case study suggest there are multiple barriers to calling 9-1-1 during accidental drug overdoses. Similar to previous studies, the most common barriers cited were fear of being arrested $(53 \%)$, breaching probation or parole $(30 \%)$, and fear of losing custody of children (24\%). Lowering the barriers to calling 9-1-1 may help to forge the path necessary to improved health care and access to resources. Ultimately, and most importantly, lives may be saved.
\end{abstract}

Keywords: Drug overdose, barriers, 9-1-1, Canada, drug policy, advocacy, case study 
In 2007, accidental overdoses and undetermined intent poisonings were the third leading cause of accidental death in Ontario (Ontario Mortality Data, 2007). Overdoses can be life threatening and the longer one experiences an overdose, the higher the risk of permanent damage or death (Darke, 2011; Darke \& Ross, 1999; Sporer, Firestone, \& Isaacs, 1996). A person who is witnessing an overdose has an opportunity to reduce harm and potentially save a life. However bystanders may not recognize the symptoms as life threatening (Beletsky, Burris, \& Kral, 2009) and typically rates of calling 9-1-1 during an overdose are low (Tobin, Davey, \& Latkin, 2005; Darke, Ross, Zador, \& Sunjic, 2000) or delayed (Pollini et. al., 2006; Tracy et. al., 2005) particularly in comparison to rates during other medical emergencies such as heart attacks (Warner-Smith, Darke, \& Day, 1997). In reviewing 953 coroner files, Darke, Ross, Zador, and Sunjic (2000) found that in only $15 \%$ of the cases was an ambulance called and no intervention occurred in $79 \%$ of cases. Using a cross-sectional survey, Tobin, Davey \& Latkin (2005) found that an ambulance was called in only $23 \%$ of overdose cases. Pollini et al. (2006) surveyed 924 people who use and found that $63.4 \%$ called but more than half of the respondents delayed calling by five minutes. Tracy et al. (2005) showed similar results, wherein $67.7 \%$ of their sample called for medical assistance, but $21.2 \%$ delayed making the call.

Research has also shown people are usually with friends or partners at the time of overdosing; bystanders and victims typically belong to similar social networks and have similar risk characteristics (Tracy et al, 2005). Those who are more likely to witness an overdose are also more likely to have overdose risk characteristics, such as previously been incarcerated, currently injecting, and having overdosed themselves (Bohnert et. al., 2011; Tracy et al., 2005). Bystanders are usually aware of the type(s) of drugs the victim has taken (Strange, Best, Man, Noble, \& Gossop, 2000; Strange, Powis, Best, Vingoe, Griffiths, Taylor, Welch, \& Gossop, 1999) and typically know how to identify the signs and symptoms (McGregor, Darke, Ali, \& Christie, 1998; Powis et al., 1999). Unfortunately, people who witness overdoses often use potentially dangerous street remedies in an attempt to revive the victim (Warner-Smith, Darke, \& Day, 2002). Common street responses include inflicting painful stimuli, walking the victim around, injecting them with saline, milk or other drugs, or putting them in a cold shower (Baca \& Grant, 2007; Pollini et al., 2006; Tracy et al., 2005). Pollini et al. (2006) showed bystanders typically walked the victim (71\%), shook them (65\%), inflicted pain (63\%), and injected with salt water (26\%). Street remedies can delay appropriate responses, such as administering CPR and calling 9-1-1, and can cause further harm.

American (Baca \& Grant, 2007; Bohnert et al., 2011; Pollini et al., 2006; Tobin et. al., 2005; Tracy et al., 2005), Australian (Darke, 2011; Darke, Ross \& Hall, 1996; McGregor et. al., 1998), and European (Sergeev, Karpets, Sarang \& Tikhonov, 2003; Togia et al., 2008) research demonstrates there are barriers to calling 9-1-1 during drug overdoses. To the researcher's knowledge, this is the first study of its kind in Canada. The most prevalent reasons for not calling 9-1-1 are fear of police involvement and subsequent arrest (Baca \& Grant, 2007; Bohnert et al., 2011; Darke, 2011; Davidson, Ochoa, Kahn, Evans, \& Moss, 2002; McGregor et al., 1998; Tobin et al., 2005; Tracy et al., 2005; ) as well as having inaccurate information, such as believing they are in control of the situation and can revive the individual (Bohnert et al., 2011; Pollini et al., 2006; Tracy et al., 2005). Overdose witnesses are also concerned they will be labeled a 'drug user' suggesting stigma can also make people less willing to call 9-1-1 (Beletsky et al., 2009). 
Follett, Piscitelli, Parkinson, \& Munger

In Waterloo Region, Guelph, and Wellington, ambulance, fire, and police are sent to overdose calls. Given the connection between fear of police involvement and not calling 9-1-1 or delaying the call, the current case study asks the question: are there barriers to calling 9-1-1 during accidental overdose situations in these areas of Southern Ontario? To answer this question, clients of local methadone clinics and outreach services $(n=291)$ were asked to complete an Overdose Response Survey from April to July 2012 inclusively. The survey asked respondents if they had witnessed an overdose and if so, if they called 9-1-1. If they did not call, the survey listed several possible barriers, which were based on previous overdose literature. Echoing the results of previous studies, the findings suggest there are multiple barriers to calling 9-1-1 during accidental drug overdoses in this region, the most common barrier being fear of arrest.

\section{Method}

The Overdose Response Survey was administered to individuals who use or have used illicit drugs or prescription drugs for recreational purposes in the area covered by the WaterlooWellington-Local Health Integration Network (LHIN). Comprised of 14 not-for-profit corporations, the LHIN is an integrated, local health unit that administers health services within Wellington County, Waterloo Region and the city of Guelph. As the surveys were administered in Waterloo, Kitchener, Cambridge, and Guelph, the LHIN is the most accurate way to describe the area in which the sample was gathered. This is a suitable location to study barriers to calling 9-1-1 during an overdose because its socio-demographics are relatively representative of Ontario and Canada (Canadian Institute for Health Information, 2011; Health System Intelligence Project, 2004) (Table 1). In terms of age-standardized hospitalizations due to injury and poising, Waterloo, Wellington-LHIN was 611 per 100,000 in 2004, while Ontario was 578.6 (Canadian Institute for Health Information, 2011; Health System Intelligence Project, 2004).

The survey explored past experience with overdose, anticipated future responses to witnessing an overdose, and demographic characteristics. Two populations were targeted for the survey, clients of local methadone clinics and people who access local outreach services including needle exchanges. Staff and students at the Waterloo Region Crime Prevention Council administered the survey to the clientele of the methadone clinics, operated by the Ontario Addiction Treatment Centres (OATC), in Cambridge and Guelph on two separate days in April and May, 2012. Outreach workers and Waterloo Region Public Health Staff in the cities of Waterloo, Kitchener, Cambridge, and Guelph also administered the surveys from April to July, 2012, inclusively. The results were then explored using frequency tables to rank the results and then compared using crosstabulations to show relationships between variables with a focus on the potential barriers to calling 9-1-1. 
Follett, Piscitelli, Parkinson, \& Munger

Table 1

Socio-Demographic Profile of Wellington-Waterloo LHIN, Ontario, and Canada

\begin{tabular}{lccc}
\hline & $\begin{array}{c}\text { Wellington- } \\
\text { Waterloo } \\
\text { LHIN (2004) }\end{array}$ & Ontario (2004) & Canada \\
\hline Labour Force Participation (age 15+) & $71.8 \%$ & $67.3 \%$ & $67.4 \%$ \\
& & & $(2007)$ \\
$\begin{array}{l}\text { Population (age 20+), completed } \\
\text { post-secondary education }\end{array}$ & $47 \%$ & $48.7 \%$ & $53 \%$ \\
$\begin{array}{l}\text { Percentage of people in low income } \\
\text { Age-standardized hospitalization rate }\end{array}$ & $10.2 \%$ & $14.4 \%$ & $(2011)$ \\
per 100,000 due to injury and poising & 611 & 578.6 & $(2010)$ \\
$\begin{array}{l}\text { Population of Aboriginal Identified } \\
\text { Pa }\end{array}$ & & & $534^{\mathrm{a}}$ \\
& $0.7 \%$ & $1.7 \%$ & $(2009)$ \\
\end{tabular}

Note. Adapted from Canadian Institute for Health Information, 2011 \& Health System Intelligence Project, 2004.

${ }^{\text {a }}$ Hospitalization due to poisoning not included.

\section{Results}

Two-hundred and ninety one individuals completed the survey of which 180 were completed at OATC clinics and 111 through outreach workers. Results showed a slight difference between males and females when comparing outreach and OATC survey participants. The OATC showed $40 \%$ of respondents as female and $60 \%$ as male whereas among outreach participants the breakdown was $31 \%$ to $69 \%$, respectively. Response rates were tracked at the OATCs. The results showed $76 \%$ of individuals approached completed the survey. Response rates were higher among females $(84 \%)$ than males $(69 \%)$. The survey respondents were $62 \%$ male and $38 \%$ female. Twenty-four percent of the sample indicated they were on probation or parole. Thirty-eight percent had children under 17. Finally, and perhaps most importantly, $65 \%$ indicated they have used illicit drugs in the past year and 59\% had used prescription drugs for recreational purposes in the past year. Seventy-one percent had used at least one illicit drug or prescription drug for recreational purposes in the past year. This suggests the target population was reached as individuals who use illicit drugs and drugs for recreational purposes are more likely to witness an overdose (Tracy et al., 2005).

The majority of respondents $(59 \%)$ had witnessed at least one overdose in their lifetime. For those respondents, $76 \%$ had witnessed between one and four overdoses. Forty-six percent of this group said that the last time they witnessed an overdose someone called 9-1-1. Therefore, in slightly more than half the cases, 9-1-1 was not called or the respondents did not know if it was called. This low calling rate is consistent with the international literature (Tobin et al., 2005; Darke et al., 2000). Just over half (54\%) of respondents indicated that if they saw an overdose in the future they would call 9-1-1 and wait for help to arrive. Among those that would not call and wait, $25 \%$ indicated they would call but not wait for help to arrive. This means approximately two thirds of respondents thought they would call 9-1-1 if they witness an overdose in future. 
The most common barrier cited by respondents was fear of being arrested, as it was stated by $28 \%$ of all respondents and $53 \%$ of respondents who would not call $9-1-1$ and wait. For respondents on probation or parole $(n=63), 53 \%$ said that they would not call and wait due to fear of arrest. Amongst the 63 individuals on probation and parole, only $37 \%$ indicated they would call and wait for help to arrive. This is significantly less than individuals who were not on probation and parole $(\mathrm{p}<.001)$. For participants who were on probation and parole, $43 \%$ said breaching their condition was a concern. Among those who would not call and wait and had children, fear of arrest was cited as a concern by $43 \%$ of respondents. For women with children, fear of arrest was cited as a concern by $73 \%$ (this number should be used with caution as only 15 women with children answered the survey and would not call 9-1-1 and wait). Fear of damaging relationship with employer or losing one's job were cited by $38 \%$ of respondents who would not call 9-1-1 and wait and were employed. Other common barrier for respondents, accounting each between $10 \%$ and $15 \%$, included getting drugs confiscated, friends, family finding out, cost of ambulance, no access to a phone, and damaging relationship with landlord. The final four barriers, identified by less than $10 \%$ of all respondents, were dislike paramedics or hospital personnel, (perceived) ability to intervene, not believing 9-1-1 would help, and possessing and administering Narcan/naloxone (Table 2). Using crosstabulation to compare the likelihood of calling 9-1-1 among individuals who have witnessed an overdose to those who have not witnessed suggests that the latter were significantly more likely to believe they would call 9-1-1 and wait for help to arrive $(\mathrm{p}<.01)$.

Individuals who have used illicit drugs in the past year are significantly less likely to call 9-1-1 and wait for help to arrive $(\mathrm{p}<.05)$ than individuals who have not used illicit drugs. Individuals who have used illicit drugs in the past year are also significantly more likely to call 9-1-1 and leave ( $\mathrm{p}=0.050)$. Similarly, younger individuals are significantly less likely to call 9-11 and wait for help to arrive $(\mathrm{p}<.01)$. They are also significantly more likely to cite fearing arrest as a reason they would not call 9-1-1 $(\mathrm{p}=0.051)$. The crosstabulations related to witnessing an overdose suggest that individuals who have witnessed an overdose are more likely to fear being arrested at an overdose $(\mathrm{p}<.01)$ and less likely to call 9-1-1 $(\mathrm{p}<.01)$. 
Follett, Piscitelli, Parkinson, \& Munger

Table 2

Barriers to Calling 9-1-1 during an Overdose

\begin{tabular}{lcc}
\hline \multicolumn{1}{c}{ Response } & $\begin{array}{c}\text { All } \\
\text { Respondents }\end{array}$ & $\begin{array}{c}\text { Excluding Would } \\
\text { Call and Wait }\end{array}$ \\
\hline Would call and wait until help arrived & $54 \%$ & - \\
Would call and leave & $14 \%$ & $25 \%$ \\
Being arrested & $28 \%$ & $53 \%$ \\
Breaching probation/parole & $16 \%$ & $30 \%$ \\
On parole/probation & $43 \%$ & $53 \%$ \\
Losing custody of children & $14 \%$ & $24 \%$ \\
With children & $22 \%$ & $43 \%$ \\
Women with children & $28 \%$ & $73 \%$ \\
Employer Relationships & $13 \%$ & $24 \%$ \\
Employed & $18 \%$ & $38 \%$ \\
Getting drugs confiscated & $14 \%$ & $23 \%$ \\
Friends, family finding out & $14 \%$ & $22 \%$ \\
Cost of ambulance & $12 \%$ & $22 \%$ \\
Don't have phone access & $15 \%$ & $21 \%$ \\
Relationship with landlord & $10 \%$ & $19 \%$ \\
Dislike paramedics/hospital & $7 \%$ & $14 \%$ \\
I can take care of it & $8 \%$ & $11 \%$ \\
Don't Believe 9-1-1 will help & $5 \%$ & $7 \%$ \\
Have Narcan/naloxone & $5 \%$ & $5 \%$ \\
\hline
\end{tabular}

Note. Percentages do not add up to 100 as respondents were asked to choose more than one if applicable.

\section{Discussion}

Rates of calling 9-1-1 during an overdose emergency are relatively low in comparison to other medical emergencies (Brown et al., 2009). This case study has identified a key normative barrier to making the call, fear of arrest. Amongst respondents who had witnessed an overdose, 9-1-1 was not called, or the respondents did not know if it was called, in more than half the cases. People who are at risk of overdosing are pushed to the margins by poverty, homelessness, Hall, Logan, Toblin, Kaplan, Kraner, Bixler, Crosby, \& Paulozzi, 2008; Kinner, Milloy, Wood, Qi, Zhang, \& Kerr, 2012; Wagner, Valente, Casanova, Partovi, Mendenhall, Hundley, Gonzalez, \& Unger, 2010) and stigma (Beletsky et al., 2009). An ineffective response to a life and death emergency is yet another form of marginalization. Overdose is a social problem and requires socially just responses. "[S]ocial and economic inequalities are to be arranged so that they are both (a) to the greatest benefit of the least advantaged and (b) attached to offices and positions open to all under conditions of fair equality of opportunity" (Rawls, 1971, p. 83). Using this lens, a death due to overdose is both a human tragedy and a societal failure.

There are policy alternatives to respond to overdose emergencies in more socially just manners. One option is to lower the barriers to calling 9-1-1 by limiting police involvement during routine calls (Beletsky et al. 2009; Davidson et al., 2002; Drug Policy Alliance, 2012; Tracy et al., 2005). In December 2003, the Vancouver Police Department (VPD) approved an 
interim overdose response policy (Vancouver Police Department, 2006). The policy aims to limit police attendance at routine overdose calls, unless the overdose was fatal or there was a safety risk to Emergency Health Services or the public. During non-fatal or routine accidental overdose calls, the police will not attend unless the emergency services requests their assistance (Vancouver Police Department, 2006). For a fatal overdose, the police investigate fully. By the end of 2004, police non-attendance during routine overdose calls was established in police procedures (Vancouver Police Department, 2006). The effectiveness of Vancouver's approach is not yet clear but the thinking behind the program suggests reduced police involvement should increase calls to 9-1-1 in the short and long term. In the short term, it should alleviate the concerns of the individuals that fear being arrested at an overdose. In the long term, the work of Tracy et al. (2005) suggests those who are aided by emergency personnel will be more likely to call in future. Indeed, although Tracy et al. (2005) found overdose victims feared criminal justice involvement, they also found that people who had been taken to the hospital were more likely to call for help in the future. They suggest "it is possible that uncertainties and fears about medical care and potential police involvement at overdose events, which commonly dissuade drug users from seeking help, were less acute among those who had already experienced an overdose and subsequent hospitalization themselves" (Tracy et al., 2005, p. 187).

Good Samaritan Drug Overdose Laws are a second policy alternative that could lower the barriers to calling 9-1-1 during an overdose. Existing in eight American states as of August 2012 (i.e., Colorado, Connecticut, Florida, Illinois, New Mexico, New York, Rhode Island, and Washington) (Smith, 2012), Good Samaritan laws provide limited legal immunity from drug prosecution for people who witness an overdose. The Drug Policy Alliance (Drug Policy Alliance, 2012) explains that these policies do not protect people from arrest for serious offenses, such as trafficking drugs. Instead, according to the Drug Policy Alliance (2012), they typically protect the caller and overdose victim from arrest for: being under the influence, simple drug possession, and possession of paraphernalia. Preliminary evaluation of Good Samaritan laws from the United States indicates that $88 \%$ of opiate users are aware of the law and are more likely to call 9-1-1 during future overdoses (Banta-Green, Kuszler, Coffin, \& Schoeppe, 2011). Concerns about negative consequences of these laws, such as prosecutions being impeded, have not been substantiated (Banta-Green et al., 2011). Instituting a Good Samaritan Drug Overdose Law, and limiting police involvement during 'routine' overdoses, may not only help to lower the barriers to access emergency services, but may also lead to better relationships between individuals at risk of overdosing and the police. Future research should examine how often overdose bystanders are arrested locally as little research has explored the interaction between bystanders and police during overdoses (Tobin et al., 2005).

This study examined the barriers to calling 9-1-1 during an overdose in the WellingtonWaterloo-LHIN area and found that fear of arrest is a particularly strong barrier. When this was cited as a concern, respondents indicated they were more likely to: call 9-1-1 and leave the victim, or they would not call. This study partially addresses a gap in Canadian literature using Waterloo Region, Guelph, and Wellington, Ontario as a case study. It is important to understand local contexts to effectively inform evidence-based interventions, as overdose risks and contextual factors are not entirely comparable between regions and countries (Marshall, Milloy, Wood, Galea, \& Kerr, 2012). While understanding the local context is important for effective community interventions, representative local findings can help inform broader policy 
Follett, Piscitelli, Parkinson, \& Munger

momentum. Instituting a Good Samaritan Law and limiting police involvement during routine overdoses may not only help to lower the barriers to access emergency services, but may, as previously noted, also improve relationships between police and individuals facing substance use issues. Ultimately, and most importantly, lives may be saved. 
Follett, Piscitelli, Parkinson, \& Munger

\section{References}

Baca, C. T., \& Grant, K. J. (2007). What heroin users tell us about overdose. Journal of Addictive Diseases, 26(4), p. 63-68.

Banta-Green, C. J., Kuszler, P. C., Coffin, P. O., \& Schoeppe, J. A. (2011). Washington's 9-1-1 Good Samaritan Drug Overdose Law - Initial Evaluation Results. Alcohol \& Drug Abuse Institute, University of Washington. Retrieved from: http://adai.uw.edu/pubs/infobriefs/ADAI-IB-2011-05.pdf

Beletsky, L., Burris, S., \& Kral, A. (2009). Closing death's door: Action steps to facilitate emergency opioid drug overdose reversal in the United States. A conference report from The Center for Health Law, Politics, and Policy, Temple University Beasley School of Law. Retrieved from: http://papers.ssrn.com/sol3/papers.cfm?abstract_id=1437163

Bohnert, A. S., Nandi, A., Tracy, M., Cerda, M., Tardiff, K. J., Vlahov, D., \& Galea, S. (2011). Policing and risk of overdose morality in urban neighborhoods. Drug and Alcohol Dependence, 113(1), 62-68.

Brown, A. L., Mann, N. C., Daya, M., Goldberg, M. R., Meischke, H., Taylor, J., Smith, K., Osganian, S., \& Cooper, L. (2000). Demographic, belief, and situational factors influencing the decision to utilize emergency medical services among chest pain patients. Circulation, 102(2), 173-178.

Canadian Institute for Health Information. (2011). Analysis in Brief: Injury Hospitalizations and Socio-Economic Status. Retrieved from https://secure.cihi.ca/free_products/Injury_aib_vE4CCF_v3_en.pdf

Davidson, P. J., Ochoa, K. C., Hahn, J. A., Evans, J. L., \& Moss, A. R. (2002). Witnessing heroin-related overdoses: The experiences of young injectors in San Francisco. Addiction, 97, 1511-1516.

Darke, S. (2011). The life of the heroin user: Typical beginnings, trajectories and outcomes. New York, NY: Cambridge University Press.

Darke, S., Ross, J., Zador, D., \& Sunjic, S. (2000). Heroin-related deaths in New South Wales, Australia, 1992-1996. Drug and Alcohol Dependence, 60, 141-150.

Darke, S., \& Ross, J. (1999). Heroin-related deaths in South Western Sydney, Australia, 19921996. Drug and Alcohol review, 18, 39-45.

Darke, S., Ross, J., \& Hall, W. (1996). Overdose among heroin users in Sydney, Australia: II. Responses to overdose. Addiction, 91(3), 413-417.

Drug Policy Alliance. (2012). 911 Good Samaritan Laws: Preventing overdose deaths, saving lives. Retrieved from http://www.drugpolicy.org/resource/ 911-good-samaritanlawspreventing-overdose-deaths-saving-lives

Hall, A. J., Logan, J. E., Toblin, R. L., Kaplan, J. A., Kraner, J. C., Bixler, D., Crosby, A. E., \& Paulozzi, L. J. (2008). Patterns of abuse among unintentional pharmaceutical overdose fatalities. Journal of the American Medical Association, 300(22), 2613-2620

Health System Intelligence Project. (2004). Population health profile: Waterloo-Wellington LHIN. Retrieved from http://www.waterloowellingtonlhin. on.ca/Page.aspx?id=1916

Kinner, S. A., Milloy M. J., Wood, E., Qi, J., Zhang, R., \& Kerr, T. (2012). Incident and risk factors for non-fatal overdose among a cohort of recently incarcerated illicit drug users. Addictive Behavious, 37, 691-696. 
Follett, Piscitelli, Parkinson, \& Munger

Marshall, B., Milloy, M. J., Wood, E., Galea, S., \& Kerr, T. (2012). Temporal and geographic shifts in urban and nonurban cocaine-related fatal overdoses in British Columbia, Canada. Ann Epidemiol, 22, 198-206.

McGregor, C., Darke, S., Ali, R., \& Christie, P. (1998). Experience of non-fatal overdose among heroin users in Adelaide, Australia: Circumstances and risk perceptions. Addiction, 93(5), 701-711.

Ontario Ministry of Health and Long Term Care IntelliHEALTH (2007). Ontario Mortality Data. Retrieved from: https://www.intellihealth.moh.gov.on.ca/SASPortal/ mainUnchallenged.do?unchallenged=yes

Pollini, R. A., McCall, L., Mehta, S. H., Celentano, D. D., Vlahov, D., \& Strathdee, S. A. (2006). Responses to overdose among injection drug users. American Journal of Preventative Medicine, 31(3), 261-264.

Powis, B., Strang, J., Griffiths, P., Taylor, C., Williamson, S., Fountain, J., \& Gossop, M. (1999). Self reported overdose among injecting drug users in London: Extent and nature of the problem. Addiction, 94(4), 471-478.

Rawls, J. (1971). A theory of justice. Cambridge, MA: Harvard University Press.

Sergeev, B., Karpets, A., Sarang, A., \& Tikhonov, M. (2003) Prevalence and circumstances of opiate overdose among injection drug users in the Russian Federation. Journal of Urban Health, 80(2), 212-219.

Smith, P. (2012, August 21). New Jersey Good Samaritan Overdose Bill Passes. StoptheDrugWar.org, Drug War Chronicle. Retrieved from http://stopthedrugwar.org/chronicle/2012/aug/21/new_jersey_good_samaritan_overdo

Sporer, K. A., Firestone, J., \& Isaacs, S. M. (1996). Out-of-hospital treatment of opioid overdoses in an urban setting. Academic Emergency Medicine, 3, 660-667.

Strange, J., Best, D., Man, L. H., Noble, A., \& Gossop, M. (2000). Peer-initiated overdose resuscitation: Fellow drug users could be mobilized to implement resuscitation. International Journal of Drug Policy, 11, 437-445.

Strange, J., Powis, B., Best, D., Vingoe, L., Griffiths, K., Taylor, C., Welch, S., \& Gossop, M. (1999). Preventing opiate overdose fatalities with take-home naloxone: Pre-launch study of possible impact and acceptability. Addiction, 94(2), 199-204.

Tobin, K. E., Davey, M. A., \& Latkin, C. A. (2005). Calling emergency medical services during drug overdose: An examination of individual, social and setting correlated. Addiction, 100, 397-404.

Togia, A., Sergentanis, T. N., Sindos, M., Ntourakis, D., Doumouchtsis, E., Sergentanis, I. N., Bachtis, C., Pyrros, D., \& Papaefstathiou, N. (2008). Drug abuse-related emergency calls: A metropolis-wide study. Prehospital and Disaster Medicine, 23(1), 36-40.

Tracy, M., Markham Piper, T., Ompad, D., Bucciarelli, A., Coffin, P. O., Vlahov, D., \& Galea, S. (2005). Circumstances of witnessed drug overdose in New York City: Implications for intervention. Drug and Alcohol Dependence, 79, 181-190.

Vancouver Police Department. (2006). Planning and research section policy report on the amendments to the Regulations and Procedures Manual (RPM). Retrieved from http://vancouver.ca/police/policeboard/documents/0648DrugOverdosePolicy2006Jun14.p df 
Follett, Piscitelli, Parkinson, \& Munger

Wagner, K. D., Valente, T. W., Casanova, M., Partovi, S. M., Mendenhall, B. M., Hundley, J. H., Gonzalez, M., \& Unger, J. B. (2010). Evaluation of an overdose prevention and response training programme for injection drug users in the Skid Row area of Los Angeles, CA. International Journal of Drug Policy, 21, 186-193.

Warner-Smith, M., Darke, S., \& Day, C. (2002). Morbidity associated with non-fatal heroin overdose. Addiction, 97, 963-967. 